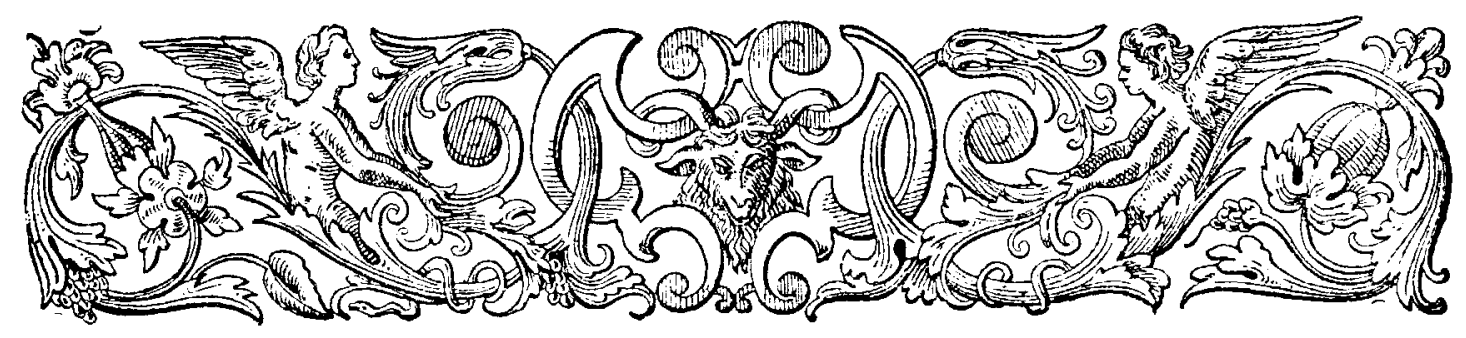

\title{
DE MUNTEN EN DE WAARDE VAN HET GELD IN HET BEGIN DER XVII ${ }^{E}$ EEUW. \\ DOOR
}

\author{
MAX ROOSES.
}

\begin{abstract}
ore wer we onoverzienbare menigte van munten er in de vorige

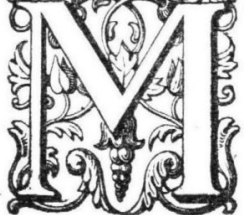
eeuwen, en meer bepaaldelijk in het begin der XVIIe eeuw, hier en elders in omloop waren. Het is niet altijd gemakkelijk zich een juist denkbeeld te vormen van de waarde, die elk hunner bezat. De oude munttarieven zijn, wel is waar, niet moeilijk te vinden, maar zij geven het wettelijk gewicht in fijn goud en fijn zilver op en leeren dus niet bijzonder veel over de waarde der speciën in gekende munteenheden. Het heeft bijgevolg zijn nut aan te duiden, welke de waarde was van elk der voornaamste geldstukken, die men hier in vorige eeuwen aantrof.

Niet minder nuttig achten wij te onderzoeken welke de waarde van het geld in die dagen was, vergeleken met die van heden. Over dit punt bestaan er zeer uiteenloopende meeningen: men hoort met onbeschroomdheid verzekeren, dat één gulden in het jaar I 600 zooveel deed als 5 en ook wel dat hij zooveel deed als Io gulden van onzen tijd. Ik ben overtuigd, dat men over het algemeen de waarde van het geld in vroeger eeuwen, ten minste in de XVIe en XVIIe eeuw, sterk overschat en wilde deze mijne zienswijze wel eens met bewijzen staven.
\end{abstract}


Het ware wenschelijk, dat de waarde van het geld in vroeger eeuwen, op degelijke gronden, wetenschappelijk worde vastgesteld. Menige inlichting, die nu al heel weinig zegt en geen helder denkbeeld opwekt, zou er duidelijk door worden. Wat beteekent voor ons, bijvoorbeeld, de zoo vaak voorkomende, en met zooveel zorg aangehaalde bijzonderheid, dat voor een schilderij zooveel honderd gulden betaald werd aan haren maker, wanneer men niet weet of één gulden van toen gelijk staat met twee, met vijf of met tien gulden van nu?

Daar ik meer dan eens zelf verplicht was opzoekingen te doen over deze twijfelachtige punten, durf ik het een niet nutteloos werk achten een kleine bijdrage te leveren tot de de oplossing van beide hooger gestelde vragen.

In het archief der familie Plantir-Moretus vond ik tal van bescheiden van aard om met nut gebezigd te worden bij deze bespreking. Een zeer eigenaardig vermeld $\mathrm{ik}$ in de eerste plaats; men zal het wel alleen aantreffen in een huis, waar eerbied voor alles wat aan de voorouders toebehoorde de gewoonte van ook schijnbaar onbeduidende dingen te bewaren zoover deed drijven als hier.

Wanneer JAN MORETUS, de eerste van dien naam, zijne kas opmaakte, eens of meermalen in de week, placht nij de verschillende muntsoorten, die hij er in aantrof, afzonderiijk op te schrijven, daarnevens de waarde ervan in guldens aan te teekenen en zoo door een reeks vermenigvuldigingen, gevolgd door eene optelling de totale som zijner ontvangsten te berekenen. De blaadjes en snippers papier, waarop hij deze cijferingen uitvoerde, bewaarde hij van I600 tot 1610 en bewaarden zijn opvolgers na hem. En ook die bescheiden familiepapieren blijken bouwstoffen voor de geschiedenis te leveren.

Ziehier als voorbeeld de kopij van een dier blaadjes.

46 dobbel ducaten en Henricus nobels..

5 half nieuwe ducaten.

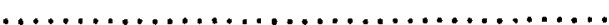

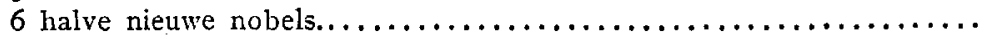

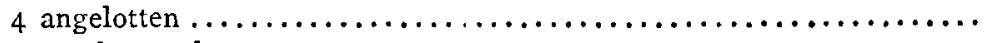

23 gouden realen $\ldots \ldots \ldots \ldots \ldots \ldots \ldots \ldots \ldots \ldots \ldots \ldots \ldots \ldots \ldots \ldots \ldots$

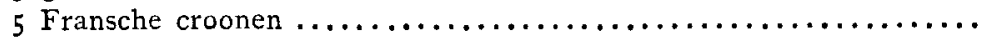

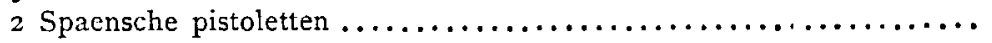

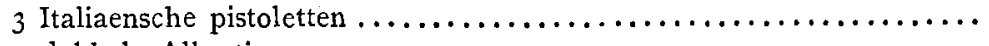

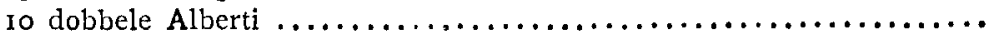

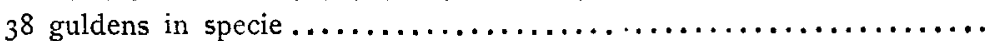

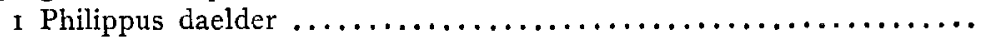

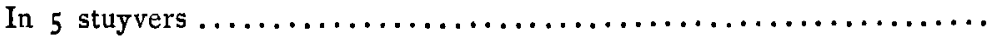

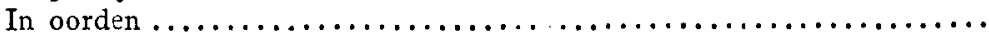

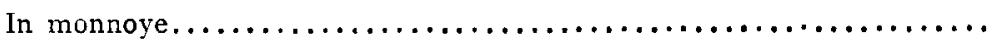

Adi 6 Novembris 1604 . fl. $345-$

I $8-2^{1 / 8}$

$24--$

$21-12$

$63-5$

$16-10$

$6-10$

$9-9$

$50-\cdots$

$38-$

$2-10$

$54--$

$4-10$

$0-141 / 2$ 
Uit deze berekeningen van Moretus maken wij de volgende lijst op der munten in onze streken in omloop in de eerste jaren der XVIIe eeuw en der waarde aan ieder geldstuk toegekend.

I dubbel Spaansch pistolet

I Spaansch pistolet of I Spaansche kroon..........

I Philippus of I Philippus daalder................

$1 / 2$ Philippus................................

I gouden reaal of gouden Philippus reaal ..........

I Philippus gulden ..........................

I Italiaansch pistolet $\ldots \ldots \ldots \ldots \ldots \ldots \ldots \ldots \ldots \ldots$.

I Italiaansche dukaat.........................

I Fransche kroon (Écu de France)...$\ldots \ldots \ldots \ldots \ldots$.

I Henricus nobel...$\ldots \ldots \ldots \ldots \ldots \ldots \ldots \ldots \ldots$.

I angelot ....................................

I oude rozen nobel (noble à la rose) ..............

I halve oude nobel............................

1 nieuwe rozen nobel..........................

I halve rozen nobel...........................

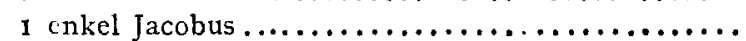

I dubbel Jacobus .............................

I Vlaamsche nobel............................

I Albertus of dubbele Albertus .................

I enkel of halve Albertus.......................

I dubbel dukaat of dukaat .....................

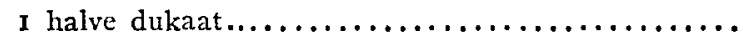

I dukaton of zilveren dukaton ...................

I halve nieuwe dukaat........................

Un quart d'Écu.............................

I rijksdaalder ...............................

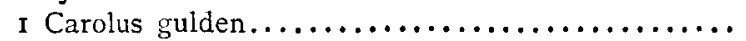

I Hongaarsche dukaat........................

I millerey (milreis) $\ldots \ldots \ldots \ldots \ldots \ldots \ldots \ldots \ldots \ldots$

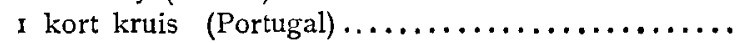

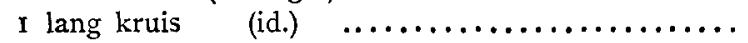

I double de Hongrie............................

I Hollandsche gulden........................

I Hollandsche daalder. ff. 6 st. Io

$3-5$

$2-10$

$1-5$

$2-15$ (of $2-16$, of $2-19$ )

$2-4$

$3-3$

$3-12 \frac{1}{2}$

$3-6$ (of $3-8$, of $3-$ I2)

$7-10$

$5-8$ (of $5-5$ )

$8-5$

$4-21 / 2$

$8--$

$4--$

$5-5$

$10-10$

6-14

$5--$

$2-10$

$7-10$

$3-15$

$2-12$ (of $2-13)$

$3-\mathrm{I} 2$ (of $3-6)$

$0-15$

$2-5$

I - I 6

$3-12$ (of $3-13)$

$3-12$

$3-10$

$3-4$

$6-8$

I - -

$\mathrm{I}-8$

Zooals men ziet wordt door MORETUS de waarde eener zelfde munt niet immer op gelijke wijze berekend. Wellicht spruit dit verschil voort uit het verschil van gewicht der stukken.

Een andere oorkonde van denzelfden tijd geeft de waarde der gouden munten naar vasten standaard op. Het is het gedrukte stuk, geplakt op de binnenzijde eener doos met schaal en met gewichtjes. Deze gewichtjes bestaan uit vierkante stukken koper; op ieder hunner is het figuur eener verschillende muntsoort afgebeeld en de zwaarte van het gewichtje staat gelijk met die, welke het afgebeelde muntstuk moet hebben. Het blaadje is gedrukt te Antwerpen bij 
Hieronymus Verdussen in 1607 . Het geeft de waarde der munten op in guldens en stuivers en in schellingen en grooten. Ziehier deze lijst:

Niewe Valuatie van de goude munte, van den lesten $\mathcal{F} u n i i$, anno 1607.

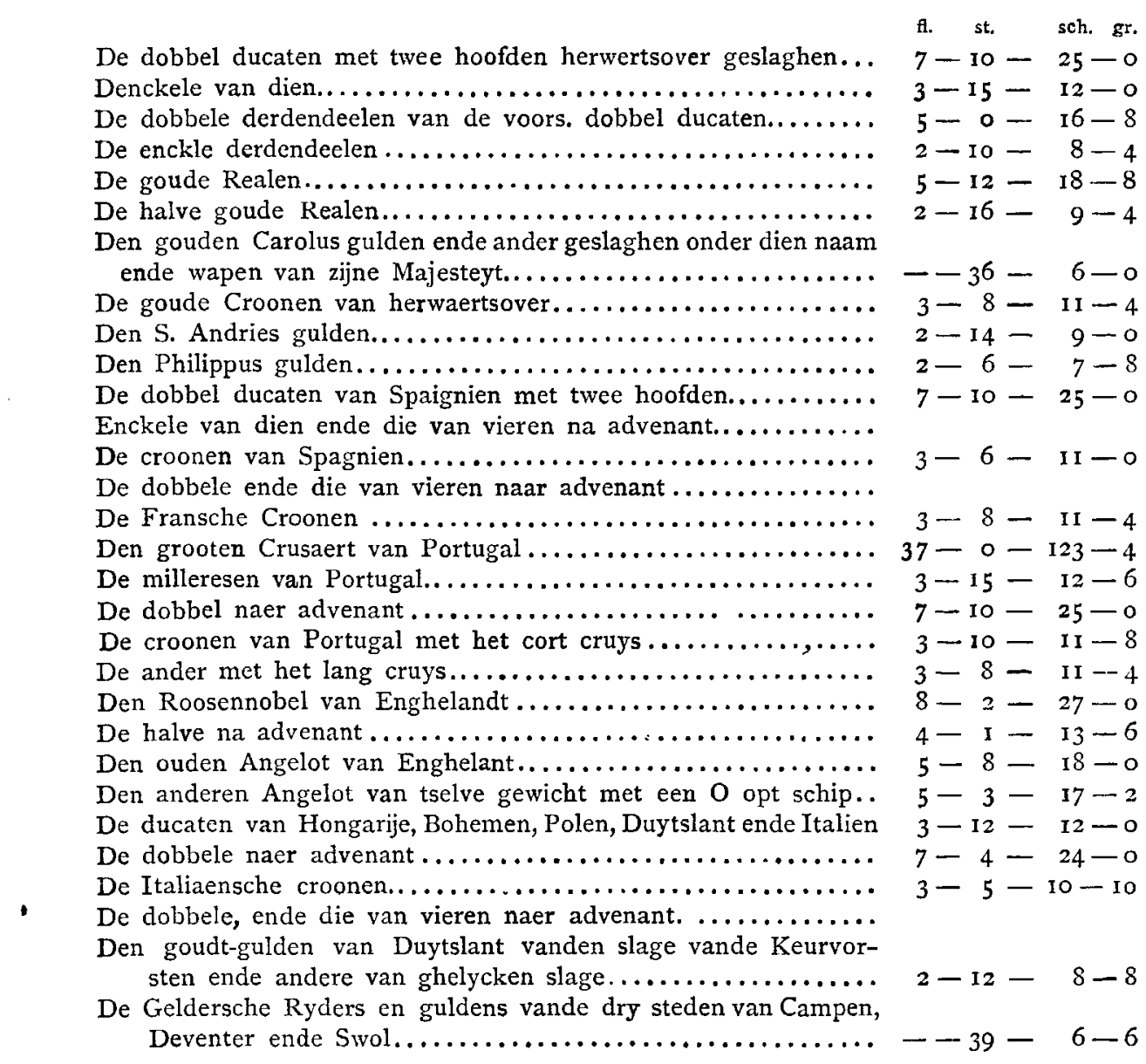

Alles ter remedien van een aesken op elck stuck. (Met Gratie ende Privilegie) Thantwerpen, bij HiERonymus VErDUSSEN, Ghegheven tot Brussel den lesten Junij 1607. Het een geteeckent Le Comte. Dander Buschere.

Uit de vergelijking dezer twee tabellen maakt men op, dat de lijst der stukken, die wezenlijk in omloop waren, sterk verschilde van die, welke ambtelijk als zoodanig werden opgegeven en dat de waarde, voor welke zij in ontvangst werden genomen, eenigszins afweek van die welke's lands bestuur er aan toekende. Dit moest er nog bijkomen om de verwarring ten top te voeren!

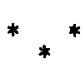


De tweede vraag tot welker oplossing wij eene bijdrage wenschen te leveren is die der waarde van het geld in het begin der XVIIe eeuw. Als de meest vertrouwbare maatstaf dezer geldt te recht het dagloon van een gewoon arbeider in eene zelfde stad in eenen vroegeren tijd vergeleken met het loon van heden. Weet men wat een metser, een timmerman, een smid en andere ambachtslieden wonnen in Antwerpen en in Amsterdam en wat zij daar nu verdienen, dan weet men ook hoeveel meer arbeids men toen voor een gulden kon bekomen dan nu. Daar het loon berekend wordt naar de behoefte van het huisgezin van den werkman, zoo kan men er uit opmaken met hoeveel toen een arbeider kon leven. Vergelijkt men dit met hetgeen de werkman nu wint, dan bekomt men de evenredigheid tusschen de waarde van het geld in de twee tijdstippen.

Als grondslag van ons onderzoek naar den toestand in het begin der XVIIe eeuw nemen wij de sommen door BALTHAZAR MORETUs betaald voor het herbouwen van een goed deel van wat nu het Museum Plantin-Moretus is. Al de rekeningen zijn bewaard, de eigenaar van het gebouw makte er zelf een algemeen overzicht van en uit de samentelling blijkt, dat hij in het geheel 305I3 guldens betaalde. Alle ambachten, die bouwwerken verrichten, zijn in die rekeningen vertegenwoordigd. Wij halen er uittreksels uit aan in de orde, waarin zij voorkomen in den band, welke ze nu bevat.

(Blz. I 53.) Den 5 Junius 1620.

Gevrocht ten huijse van sinnoer Moerentorf (MORETus) op de Vrijdachs mert. In den Passer.

PAUwels vanden SAnden metser 2 daghen................. 2 gl. 8 st.

GeERT den metser gevrocht 2 daghen..................... 2 gl. 8 st.

BastiaEn metser gevrocht $z_{4}$ daghen....................... o gl. 18 st. ROELANT dinder gevrocht 2 daghen..................... I gl. 8 st. PeEter dinder gevrocht 2 daghen...................... I gl. 8 st.

De sten schonmaeker (steen-schoonmaker) .................. 8 st.

De rekening loopt over 53 weken. Zelden werkt een zelfde man de zes volle dagen der week. Des zomers en des winters is het dagloon gelijk. Heel het jaar door winnen de metsers I gulden en 4 stuivers, de dienders 14 stuivers per dag.

(Blz. I97-216). Rekeninghe van arbeytsloon van WILLEM VANDEN BOGAERDE timmerman.

1620 (van den $2 \mathrm{n}$ ) tot den $8 \mathrm{n}$ Augustus.

Noch hebbe ick WILLEM ghevrocht 5 daghen tot 28 st. - 7 gul.

Noch heeft Cornelis gevrocht 6 daghen tot 22 st. -6 gul. I2 st.

Noch heett LAUREYS gevrocht 6 daghen tot 22 st. -6 gul. I 2 st.

Noch heeft Hans MiCHIELSENS gevrocht 2 daghen tot 22 st. -2 gul. 4 st.

Noch heeft HaNs GhenOels - 2 dagen tot 22 st. -2 gul. 4 st.

Noch heeft HANS DE WINTER - 4 dagen tot 20 st. - 4 gul.

Noch heeft BALTEN gevrocht 2 dagen tot 20 st. - 2 gul.

Noch heeft JACUs gevrocht $5 \frac{3}{4}$ dagen tot 18 st. -5 gul. 3 st. $\frac{1}{2}$ 
Ook hier werkt een werkman slechts bij uitzondering, in denzelfden bouw ten minste, zes dagen in de week. In de wintermaanden blijft, evenals midden in den zomer, het loon van een baas 28 stuivers, dat van den vollen timmermansgast 22 stuivers; gasten van minder bekwaamheid winnen 20, I9, 18 stuivers.

Volgens de rekening van JACQUES VAN NUYS, den leemplakker (Blz. 285), verdiende hij 24 stuivers per dag, zijn werkman 22 stuivers, de diender 14 stuivers, de jongen to stuivers.

Volgens de rekening der steenhouwers EvERAERT VAN EyCK en CorNELIS VANDEN EVNDE (Blz. 30I) wint een steenhouwer I 5 stuivers daags.

De loodgieter Sebastiaen Hermans (Blz. 307) rekent voor een dag werkens met drieën 2 gulden.

De schaliedekker ABRAHAM VAN DEN BosCH (Blz. 335) rekent voor zijne gasten 24 stuivers daags, voor den diender 12 stuivers.

MORETUs' eigen werklieden der Plantijnsche drukkerij werken per stuk en bij paren, de drukker en zijn inktroller; zij winnen in 1620 , gemiddeld, de eenen 8 , de anderen 14 gulden in de week met hun beiden. De beste zetters winnen nagenoeg 10 gulden in de week, de mindere 8 of 6 gulden.

Wij komen dus tot de slotsom, dat de goedbetaalde werklieden metsers, timmerlieden, plafonneurs, schaliedekkers, drukkers, één gulden en twee stuivers of één gulden en vier stuivers wonnen, de steenhouwers, de dienders en mindere werklieden verdienen 12, I4, I5, 16, I 8 stuivers. De Brabantsche gulden deed 20 stuivers, een stuiver vier oorden of negen onzer centiemen.

Wanneer wij nagaan, dat tegenwoordig ten onzent de metsers, timmerlieden en andere hooger genoemde ambachtslieden door den band twee of twee en een halven gulden per dag verdienen in de beste voorwaarden, dan komen wij tot de slotsom, dat in I 893 onze werklieden dubbel zooveel guldens winnen als hunne voorzaten in 1620 en het geld toen, niet het tiendubbel noch het vijfdubbel, maar enkel het dubbel der waarde had van nu. Herinnert men zich, dat het loon onzer werklieden over een menschen-leeftijd nagenoeg de helft was van hetgeen het nu is, dan mag men bevestigen dat van 1820 tot 1850 de waarde van het geld nagenoeg dezelfde was als van 1620 tot 1650 . Ziedaar een uitslag, die menigeen vreemd zal doen opkijken en het algemeen aangenomen stelsel over de geldwaarde omstoot; maar de zaak staat nu eenmaal zoo. Daar ik zelf moeite had aan de nauwkeurigheid mijner berekening te gelooven, heb ik deze op velerlei wijze getoetst en ook voor de naastbij liggende tijdstippen gemaakt. Immer ben ik tot dezelfde slotsom gekomen, wanneer ik het dagloon der werklieden tot grondslag mijner berekening nam.

Een andere wijze om de toenmalige waarde van het geld vast te stellen 
is na te gaan wat de meest gebruikelijke waren kostten. De gronden zijn hier onvaster, en de uitslagen schijnen ook wel eenigszins anders te zijn, maar groot is toch het verschil niet.

Ziehier eenige posten uit de rekening, die JAN MORETUS II, als deken der St. Lucasgilde in 16 I 7 betaalde, na afloop der maaltijd van het St. Lucasfeest.

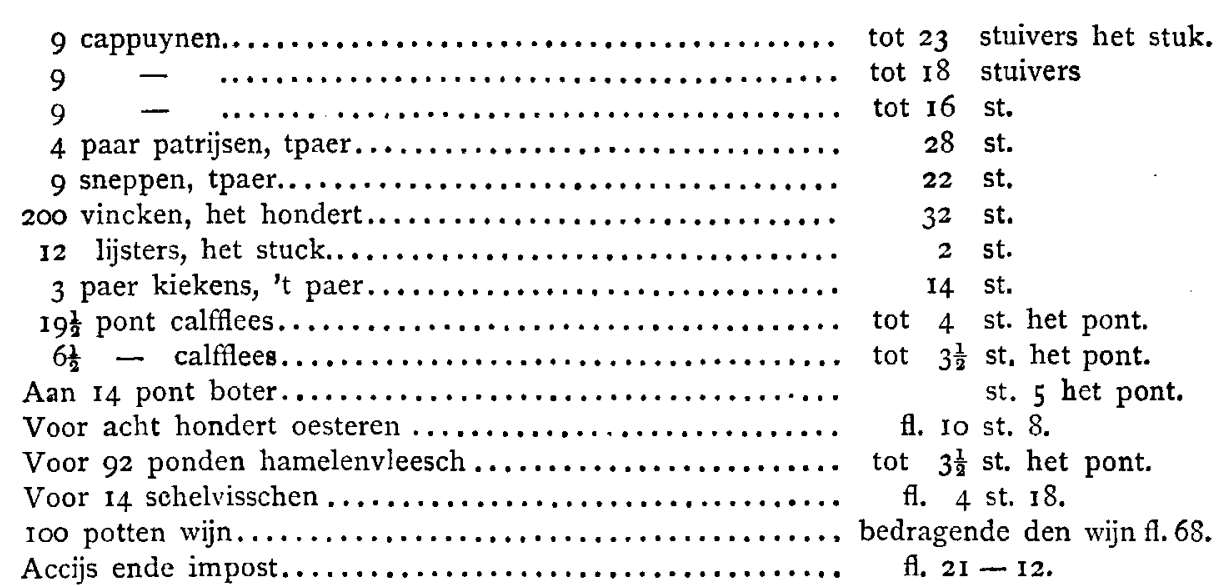

Een aam Rijnwijn gold 72, 74, of 78, gulden. Een pot kostte 1 gulden.

In de rekeningen van het sterfhuis van JAN MoRetus I, October I6Io, lezen wij, dat men de volgende prijzen betaalde:

Het zwart laken 3 gulden 14 stuivers de el (van 70 centimeters.)

Het fijn zwart laken 9 gulden 15 st. de el.

Een fijner soort zwart laken i I gulden de el.

Een soort grauw laken 3 gulden.

Een soort wit laken 4 gulden to stuivers.

In 1618 betaalde JAN MORETUS:

Een paar schoenen voor zijn jongste dochter................. Io stuivers.

Een paar graw schoenen voor zijn oudste dochter............... 14 -

Een paar violette gepiqueerde schoenen voor jufvrouw ............ 30 -

Een paar geborduurde schoenen $\quad$ idem $\quad \ldots \ldots \ldots \ldots \ldots \ldots$ 30 -

Een paar schoenen voor mijnheer........................ 45 -

Een paar schoenen voor den knecht..................... 45 -

Eeu paar gefoureerde schoenen voor mijnheer................. 45 -

Een paar Spaansch leeren schoenen idem $\quad \ldots \ldots \ldots \ldots \ldots \ldots \ldots \ldots \ldots .45$.

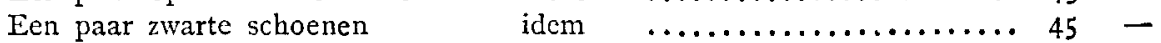

De satijn kostte, in 1624 , I6 of I7 stuivers de el, de ongeschoren fluweel 9 gulden, de faliezijde 7 gulden, het lijnwaad I4 of I 5 stuivers, het grauw lijnwaad 20 stuivers.

Honderd pond rijst kostte, in I6IO, I4 gulden. 
Een pond kaneel $2 \frac{1}{2}$ gulden.

Een pond saffraan 2 I gulden.

Er waren tarwebrooden van een halven stuiver, een stuiver en twee stuivers.

Een pot melk (ongeveer anderhalve liter) kostte I stuiver.

In de rekeningen van den bouw van BALThASAR MORETUS werd in I620 betaald :

voor een pond lood 2 stuivers

voor een pond bewerkt ijzer $2 \frac{11}{4}$ stuivers

voor duizend gemeene baksteenen fl. 4 st. 5

voor duizend "cleere" steenen fl. 6

voor duizend Hollandsche steenen fl. 3 st. I2

voor duizend dubbel steenen fl. 8 .

Men ziet, dat de verhouding der prijzen van die tijden tot de tegenwoordige zeer uiteenloopende is. Sommige waren, zooals laken en baksteenen, betaalde men even zooveel als nu, of zelfs meer. Een schelvisch kostte 7 stuivers, een pond kalfsvleesch $3^{\frac{1}{2}}$ of 4 stuivers, I kapuin 16 tot 23 stuivers, een pond boter 5 stuivers; men mag zeggen dat dezelfde waren nu eens anderhalve maal zooveel, dan weer twee of driemaal zooveel worden betaald. Schoenen kostten slechts een derde of een vierde van hunnen tegenwoordigen prijs. Over het algemeen schijnt de prijs der waren in guldens minder dan de helft te bedragen van nu. Houdt men rekening van het feit, dat de werkman de helft won van wat hij nu wint, en dat de levensbehoeften de helft of een derde kostten van wat men ze nu betaait, dan mag men aannemen, dat de waarde van het geld in het begin der XVIIe eeuw, vergeleken met die van heden, tusschen het twee- en het driedubbel moet gesteld worden, en zeker zal men ze niet te laag schatten, wanneer men ze voor twee en een kwart maal grooter houdt. Vergelijkt men het dagloon der ambachtslieden met den prijs van eetwaren en kleergoed, dan mag men besluiten, dat de arbeiders het toen beter stelden dan nu.

Wanneer men op die grondslagen berekent wat er aan de kunstenaars in het begin der XVIIe eeuw werd betaald voor hun werk, dan vindt men dat zij door den band minder rekenden dan nu. Het is waar, dat zij toen over het algemeen veel meer werk leverden en op die wijze terugwonnen wat zij verloren op den prijs van elk stuk.

RUBENS ontving voor zijn in I6I I besteld meesterstuk de drieluik de Afdoening van het Kruis in de hoofdkerk van Antwerpen 2400 gulden (van 20 stuivers; in ons geld 1.80 frank) wat nu nagenoeg met 5400 gulden zou gelijk staan. Een ander meesterstuk de Laatste Communie van Sint Franciscus in het Antwerpsch 
Museum werd hem, in 1619,750 gulden betaald. Naarmate zijn naam en faam stegen, stegen ook de prijzen, die hij rekende. De Medicis-galerij, uit den Louvre bracht hem in $1622-162520.000$ Fransche kronen op: an 3 gulden 8 stuivers de kroon makkt dit 68.000 gulden, ongeveer I 50.000 gulden van nu, wat niet bijzonder slecht betaald mag heeten. Voor loopend werk van weinig belang rekende hij verbazend kleine prijzen. De portretten, die hij rond $\mathrm{I} 6 \mathrm{I} \epsilon$ voor zijnen vriend BALTHASAR MORETUS schilderde, werden hem I4 gulden 8 stuivers het stuk betaald; die, welke hij na 1630 schilderde, kwamen op 24 gulden. Voor een teekening in-folio rekende hij 20 gulden, voor eene in-quarto I2, voor eene in-octavo 8 , voor een in-24 5 gulden.

VAN DIJCK ontving voor zijnen Gelukzaligen Hermanus Fosephus (Rijksmuseum van Weenen) 150 gulden in 1630 ; voor zijn Kruisrechting (Hoofdkerk van Kortrijk) 600 gulden; voor zijn Kalvariënberg (St. Michielskerk, Gent) 800 gulden, voor zijn portret van Karel I (in den Louvre) Ioo pond sterling.

JORDAENS ontving voor het groote stuk uit de Oranjezaal in het huis ten Bosch 3000 gulden, voor elk zijner stukken uit de Geschiedenis der Batavieren op het Amsterdamsch stadhuis 600 gulden.

Deze waren de groote goden. BOEREN BREUGHEL ontving 150 gulden het stuk voor belangrijke werken; het magistraat van Antwerpen betaalde 300 gulden aan FRANS SNIJDERS voor een zijner voornaamste wildstukken. ThOMAS WiLleborts ontvangt van MORETus 96 gulden voor twee portretten. Aan ERASMUS QUELLIN wordt 15 of 16 gulden voor een geschilderd portret en een teekening, en $25^{\circ}$ gulden voor een groote schilderij toegekend. Niet anders ging het toe met de beeldhouwers en de graveurs. HANS VAN MILDERT ontving in 1622 150 gulden voor drie borstbeelden. Aan ARTUs Queltin, den beroemden kunstenaar, werd door

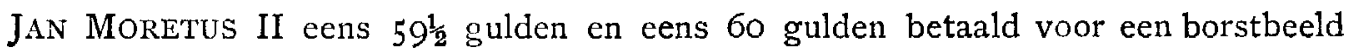
in witten steen. Voor het groote beeldhouwwerk, boven de poort van het museum Plantin-Moretus prijkende, rekende hij 150 gulden. Aan de groote graveurs van Rubens, Theodoor en Cornelis Galle, Pieter de Jode, Lucas Vorsterman werd voor een titelplaat in-folio van 75 tot Ioo gulden betaald.

Voor al deze werken zou nu zeker het vierdubbel gerekend worden. Maar waar is het dat, indien de kunstenaars van eersten rang geld wonnen en verteerden als groote heeren, die van minderen rang veel dichter stonden bij den ambachtsman dan dit in onze dagen het geval is.

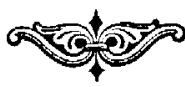

